\title{
Popularity and knowledge concerning complications of body modifications among young adults
}

\begin{abstract}
Introduction. Body modifications are practices leading to transient or permanent change of various parts of human body. The most popular forms of body modifications are tattooing and piercing.

Aim. The aim of the study is to determine the frequency of the most popular body modifications (tattoos and piercing) among young adults aged 18-32 years and to collect and analyze their opinions concerning body modifications and to determine their knowledge about the complications during these procedures.

Material and methods. The study was conducted in February 2017 among 251 individuals: 146 females (58.17\%) and 105 males $(41.83 \%)$. An original questionnaire was used. It consisted of questions about body modifications. Researchers recorded body modifications the respondents have had. Participation in the study was voluntary and anonymous. Participants were randomly selected. Results were analyzed with STATISTICA 12.5 and ANOVA program; $\mathrm{p}<0.05$ was considered statistically significant.

Results. The number of 23 examined individuals (10 men and 13 women) had tattoos $(9.16 \%)$. The mean number of tattoos was $1.6 \pm 0.6$ for women and $2 \pm 1.1$ for men. As many as 128 individuals had ear piercing (51\%), including 6 males and 122 females. The number of 13 people $(5.18 \%)$ had piercing in places other than ears. Piercing is significantly more common than tattooing. As many as 109 individuals $(43.43 \%)$ did not have tattoos or body piercing. The total number of 106 respondents $(42.23 \%)$ liked tattoos, ear piercing $168(66.93 \%)$, piercing of other parts of the body $41(16.33 \%)$, and other body modifications $8(3.19 \%)$ individuals. As many as $221(88.05 \%)$ individuals claimed that they knew the complications of body modifications.

Conclusions. Body modifications are popular among young adults, especially among females. The most positively assessed by respondents were earnings and tattoos, what correlates with their occurrence in this group of people. The vast majority of respondents consider that they know the complications of body modifications.
\end{abstract}

Keywords: tattooing, piercing, young adults.

DOI: $10.1515 /$ pjph-2017-0015

\section{INTRODUCTION}

Body modifications are practices leading to transient or permanent 'decorating' of various parts of human body. These modifications are not just hair styling, clothing, makeup, nail art, body piercing, tattoos, but also scarification, bone deformation, subcutaneous implants with protruding spikes, cutting or amputation of parts of organs, silicone components, subcutaneous implants, and split tongues. The most popular forms of body modification are tattoos and piercing [1,2].

Within last twenty years, the prevalence of individuals with tattoos in the general population has increased in Europe, Australia and the US [1]. A tattoo is done by inserting indelible ink into the dermis in order to change its pigmentation. Tattoos are done for cultural, social, and religious purposes [3].

Piercing has become popular amongst young adults and teenagers as a method of self-expression. Common sites for body piercing are ear lobes, eyebrows, noses, tongue, navels, nipples, and the genitals [4].

\section{AIM}

The study aimed to assess the frequency of the most popular body modifications (tattoos and piercing) among young adults aged 18-32 years in Lublin, Poland and to collect and analyze the respondents' opinions about body modifications.

\section{MATERIAL AND METHODS}

The study was conducted in February 2017 among 251 individuals: 146 females (58.17\%) and 105 males (41.83\%). An original questionnaire with questions about individuals' opinions concerning body modifications was used in the study.

The questionnaire consisted of 4 major parts:

1. What is your opinion about tattoos?

2. What is your opinion about ear piercing?

3. What is your opinion about body piercing in parts different than ears?

4. What is your opinion about other body modifications such as subcutaneous implants, split tongue?

\footnotetext{
${ }^{1}$ Students' Scientific Association at the Chair and Department of Hygiene, Medical University of Lublin, Poland

${ }^{2}$ Chair and Department of Hygiene, Medical University of Lublin, Poland
} 
Individuals selected one answer to each item. They could select one of the following: "I definitely like it", "I like it", "I do not know", "I do not like it", "I definitely do not like it".

The next questions were the following:

1. Do you know any negative health effects or possible infections during body modifications? - Individuals selected one answer: "yes" or "no".

2. What negative health effects or infections can occur during body modification? You can mark more than one answer. - Individuals could select from 8 answers: "These interventions are always safe", "These interventions are safe if they are performed by a capable person", "HBV infection", "HCV infection", "HIV infection", "CMV infection", "Bacterial infection in place of body modification", "Sepsis".

There were also questions about body modifications the respondents have had. Participation in the study was voluntary and anonymous. Participants were randomly selected. Selection criteria were: age 18-32 and living in the territory of Lubelskie voivodship. Results were analyzed with STATISTICA 12.5 and ANOVA program; $p<0.05$ was considered statistically significant.

\section{RESULTS}

The mean age $( \pm \mathrm{SD})$ of participants was $22.1 \pm 2.2$ years (min. 18, max 32 years). When it comes to interviewed individuals, 23 of them had tattoos $(9.16 \%)$ including 10 males $(9.52 \%)$ and 13 females $(8.9 \%)$. The mean number of tattoos was $1.6 \pm 0.6$ for females and $2 \pm 1.1$ for males. As many as 7 males (70\%) and 6 females (46\%) had tattoos in visible places.

The total number of 128 individuals had ear piercing (51\%), including 6 males and 122 females. Among them 6 individuals $(2.39 \%)$ had 1 earring in one ear, 8 individuals $(3.19 \%)$ had in one ear more than 1 earring and none in another one, 26 individuals $(10.36 \%)$ had in their ears more than one earring in each ear, while 88 individuals (35.06\%) had one earring in each ear. The number of women with ear piercing $(82.88 \%)$ was significantly higher than that of men $(5.71 \%) \mathrm{p}<0.05$.

The mean number of earrings in one ear was $1.17 \pm 0.41$ in males (min. 1, max. 2) and $2.53 \pm 0.96$ in females (min. 1, max. 5). As many as 13 women (5.18\%) had piercing in other parts of the body; 3 women had nose piercing $(2.05 \%)$ and $7(4.79 \%)$ had navel piercing. The number of 6 individuals $(2.39 \%)-5$ men $(4.76 \%)$ and 1 woman $(0.68 \%)$ had piercing in different parts than ears, nose, lips, tongue, navel and eyebrows. As many as 109 individuals (43.43\%) did not have tattoos or body piercing. Piercing was significantly more common than tattoos $(\mathrm{p}<0.05)$.

Tattoos are accepted by 106 respondents (42.23\%) and are not accepted by $53(21.12 \%)$. As many as 168 participants (66.93\%) like earrings and $11(4.38 \%)$ do not; body piercing in places other than ears are liked by 41 people $(16.33 \%)$ and $109(43.43 \%)$, respectively. Other body modifications are accepted by $8(3.19 \%)$ individuals and are not by $205(81.67 \%)$ (Fig. 1).

Significantly higher number of male participants did not like tatoos $(24.26 \%)$ than women $(18.49 \%)$. As many as 123 women (84.25\%) liked earring and only 45 men (42.45\%) did. Only men had negative opinion about ear piercing.

Body piercing in other but ear parts of the body was not accepted by men $(49.52 \%)$. They statistically significantly more

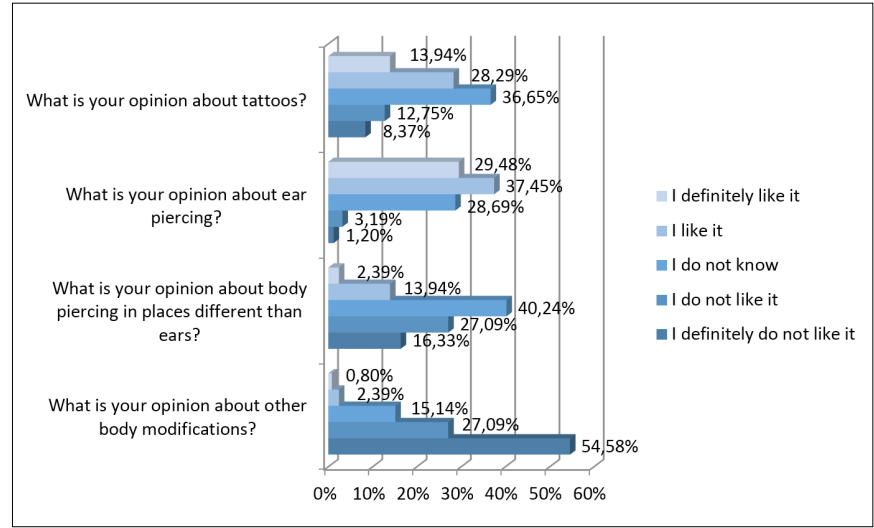

FIGURE 1. Opinions of surveyed individuals about body modifications.

often chose the answer „Idefinitely do not like it” (24.76\%), while women's opinion was alike in $10.27 \%$ of cases. However, women were significantly more critical to other body modifications $-82.88 \%$ vs $80 \%$. Men were more likely to choose „I definitely do not like it”answer: $57.14 \%$ vs $52.74 \%$.

The total number of 221 individuals $(88.05 \%)$ claimed that they knew the complications of body modifications.

All the respondents knew that body modifications procedures are not always safe. As many as 118 young adults $(47.01 \%)$ believed that these interventions are safe if they are performed by a capable person. Only every fifth one knows that he/she could end up with Cytomegalovirus infections during body modifications procedures and $56.57 \%$ of respondents did not know that after these procedures a person can come down with sepsis. More than half of respondents knew that after these interventions they may come down with $\mathrm{HBV}, \mathrm{HCV}$ and HIV infections, and they could end up with bacterial infection in place of body modification (Fig. 2).

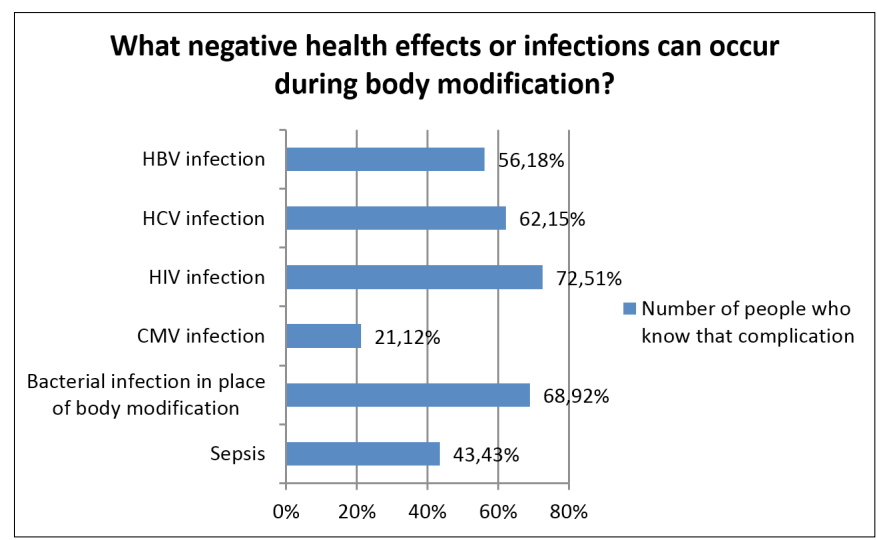

FIGURE 2. Number of young adults who knew negative health effects or infections which can occur during body modification.

\section{DISCUSSION}

The authors collected questionnaires about body modifications filled by the participants. In the present study the rates were $52.99 \%$ for body piercing and $9.16 \%$ for tattooing. In the developed countries, the prevalence of body piercing is reported to be between $4.3 \%-51 \%$ [5]. Studies have indicated differing prevalence rates of $26.1 \%$ [6], 63\% [7], and $8.2 \%$, for piercing, and $13.2 \%$ [6], 73\% [7], 4.3\% [8] for tattooing among the young adults population. Our results show that the rates of piercing among young adults in Lublin are higher than those reported by other authors and are average as for tattooing. 
An observation of the parts of the body on which individuals had piercing, showed that the majority had their earrings in the ear cartilage (51\%). Other study had similar results $[8,9]$. Tattoos are mostly seen on the shoulders, back, arms and legs [9].

The reasons why people are getting pierced and tattooed are the following: striving to be up to date with fashion trends, the desire to beautify their body to make certain impression or to create new image, mimicking their idols, overcoming their complexes, the desire to stand out, or to express spirituality and cultural tradition [10,11]. Our study shows what are young adults' opinions about that form of body modifications. No similar articles were found.

The majority of medical literature on tattooing and body piercing has focused on the risks and complications of these procedures. Tattooing can cause important dermatological complications, for example various forms of hypersensitivity reactions, allergic contact dermatitis, lichenoid, granulomatous skin disease, and also formation of hypertrophic scars and keloid $[1,3]$. Cutaneous infections usually develop within days to weeks after the procedure of tattooing. Infectious complications include different viral infections (verruca vulgaris, molluscum contagiosum, hepatitis $\mathrm{B}$ and $\mathrm{C}$, herpes simplex or infection with human immunodeficiency virus), bacterial infections (Streptococcus, Staphylococcus, Pseudomonas aeruginosa, cutaneous tuberculosis, syphilis, pyoderma, mycobacteriosis), and fungal infections (dermatophytosis, sporotrichosis) $[1,12,13]$. Complications of piercing vary depending on the hygiene regimens, materials used in the body-piercing site, experience of the practitioner, and aftercare by the recipient. Local infections are common problem too. Systemic complications include allergic contact dermatitis (from nickel, gold or silver, latex), bleeding, nerve damage, and scarring [2]. What is important, body piercing carried out in unhygienic conditions can cause hepatitis B or $\mathrm{C}$ virus infection, or HIV infection [14]. Our study confirmed that not all young adults know the negative effects of body modifications procedures. That is why, effective programs have to be established to make body piercing and tattooing a safe practice.

\section{CONCLUSIONS}

Body modifications are becoming more and more popular among young adults. The most positive opinions among young adults have ear piercing and tattoos, what correlates with their occurrence in this group. However, such modifications can result in bacterial, viral or fungal infections of the skin, allergic reactions, systemic reactions of the organism. The majority of respondents claimed that they know the complications of body modifications but our study showed that there are great needs for public education about the health effects of improper body modifications.

\section{REFERENCES}

1. Oanţă A, Irimie M. Tinea on a Tattoo. Acta Dermatovenerol Croat. 2016;24 (3):223-4.

2. Holbrook J, Minocha J, Laumann A. Body piercing: complications and prevention of health risks. Am J Clin Dermatol. 2012;13(1):1-17.

3. Ayanlowo OO, Gold-Olufadi SA, Akinkugbe AO, et al. Growing trend of tattooing and its complications in Nigeria. Int J Dermatol. 2017;56(7):70914.

4. Randall JA, Sheffield D. Just a personal thing? A qualitative account of health behaviours and values associated with body piercing. Perspect Public Health. 2013;133:110-5.

5. Bone A, Ncube F, Nichols T, Noah ND. Body piercing in England: A survey of piercing at sites other than earlobe. BM. 2008;336:1426-8.

6. Carroll ST, Riffenburgh RH, Roberts TA, Myhre EB. Tattoos and body piercings as indicators of adolescent risk-taking behaviors. Pediatrics. 2002;109:1021-7.

7. Greif J, Hewitt W, Armstrong ML. Tattooing and body piercing. Body art practices among college students. Clin Nurs Res.1999;8:368-85.

8. Balci S, Sari E, Mutlu B. Comparison of risk-taking behaviour and frequency of piercing and tattooing among university students. J Pak Med Assoc. 2015;65(6):587-92.

9. Mayers LB, Chiffriller SH. Body art (body piercing and tattooing) among undergraduate university students: "Then and Now". J Adolesc Health. 2008;42:201-3.

10. Wohlrab S, Stahl J, Kappeler PM. Modifying the body: motivations for getting tattooed and pierced. Body Image. 2007;4(1):87-95.

11. Szewczyk K. Body piercing as a form of escape into the body. Fam Med Prim Care Rev. 2005;7(2):110-5.

12. Kluger N. Cutaneous infections related to permanent tattooing. Med Mal Infect. 2011;41(3):115-22.

13. Alimohamadi Y, Tabatabaee H, AfsarKazerooni P, et al. Epidemiologic characteristics of HIV-positive patients referring to behavioral diseases consultation center in Shiraz, Iran. Med J Islam Repub Iran. 2014; 28:147.

14. Guiard-Schmid JB, Picard H, Slama L, et al. Piercing and its infectious complications. A public health issue in France. Presse Med. 2000;29(35):1948-56

\section{Corresponding author}

Barbara Nieradko-Iwanicka

Chair and Department of Hygiene, Medical University of Lublin

11 Radziwiłłowska Str., 20-080 Lublin, Poland

tel: +48814486130

E-mail: bnieradkoiwanicka@wp.pl 